\title{
Análise da gestão dos resíduos sólidos gerados no processo de produção e programas de minimização de impactos ambientais de uma indústria de calçados do Estado do Ceará
}

Management analysis of solid waste generated in the production process and programs to minimize environmental impacts of a shoe industry in the State of Ceará

Análisis de gestión de residuos sólidos generados en el proceso de producción y programas para minimizar los impactos ambientales de una industria de calzado en el Estado de Ceará

Diego Freire Martins Mestrando, Universidade Federal do Rio Grande do Norte (UFRN), Brasil Diegofreire456@gmail.com

Juceline Batista dos Santos Bastos Professora Doutora, Instituto Federal de Educação, Ciência e Tecnologia do Ceará (IFCE), Brasil mrosario@gmai.com

Whana Rayara Rabelo de Oliveira Especialista, Instituto Federal de Educação, Ciência e Tecnologia do Ceará (IFCE), Brasil rabelowhana@gmail.com 


\title{
Revista Científica ANAP Brasil
}

\author{
ISSN 1984-3240 - Volume 13, número 29, 2020
}

\section{RESUMO}

As atividades industriais provocam inúmeros impactos positivos na economia e ganhos sociais para um país, entretanto, podem ser sinônimos de perdas ambientais consideráveis. A indústria de calçados se destaca com cerca de 6 mil empresas no Brasil, sendo o Ceará o estado de maior produção do país com 27\% em 2018. Esse tipo de indústria tem gerado por volta de 300 toneladas/dia de resíduos sólidos no Brasil. Isso indica um desafio ambiental sobre como gerir os resíduos de modo adequado. Esta pesquisa objetivou analisar a gestão de resíduos sólidos gerados no processo de produção e programas de minimização de impactos ambientais de uma indústria de calçados do Estado do Ceará. A metodologia empregada foi dividida em três etapas: (i) qualitativo dos resíduos sólidos, (ii) quantitativo e custos dos resíduos e (iii) avaliação dos programas de minimização de impactos da empresa. Em conclusão, teve-se um adequado armazenamento, coleta e múltiplas destinações finais para os resíduos, com destaque para o coprocessamento e o reaproveitamento de resíduos em outras etapas do processo produtivo. Foram desenvolvidos programas de minimização dos impactos ambientais por meio do "D'Olho na Qualidade"; "Energia e Carbono"; e "Automonitoramento de Efluentes". O principal desafio da empresa no gerenciamento dos resíduos sólidos foi tornar a visão mais sistemática nas etapas do ciclo produtivo dos setores: a origem das matérias-primas, opção por insumos alternativos, tornar mais eficientes os processos de transformação dos produtos e ampliar os programas de logística reversa e responsabilidade pós-uso.

PALAVRAS-CHAVE: Indústria de Calçados. Resíduos Sólidos. Impactos Ambientais. Gestão Ambiental.

\section{ABSTRACT}

Industrial activities have numerous positive impacts on the economy and social gains for a country, however, they can be synonymous with considerable environmental losses. The shoe industry stands out with around 6 thousand companies in Brazil, with Ceará being the state with the largest production in the country with $27 \%$ in 2018 . This type of industry has generated around 300 tons/day of solid waste in Brazil. This indicates an environmental challenge on how to manage waste in an appropriate manner. This research aimed to analyze the management of solid waste generated in the production process and programs to minimize environmental impacts of a footwear industry in the State of Ceará. The methodology used was divided into three stages: (i) qualitative of solid waste, (ii) quantitative and costs of the wastes and (iii) evaluation of the company's impact minimization programs. In conclusion, there was adequate storage, collection and multiple final destinations for waste, with emphasis on co-processing and reuse of waste in other stages of the production process. Programs were developed to minimize environmental impacts through "D'Olho in Quality", "Energy and Carbon" and "Effluents Self-Monitoring". The company's main challenge in the management of solid waste was to make the vision more systematic in the stages of the productive cycle of the sectors: the origin of raw materials, alternative supply options, make product transformation processes more efficient and expand the reverse logistics and post-use responsibility programs.

KEY-WORDS: Shoe Industry. Solid Waste. Environmental Impacts. Environmental Management.

\section{RESUMEN}

Las actividades industriales tienen numerosos impactos positivos en la economía y las ganancias sociales para un país, sin embargo, pueden ser sinónimo de considerables pérdidas ambientales. La industria de calzado se destaca con alrededor de 6 mil empresas en Brasil, siendo Ceará el estado con la producción más grande del país con un 27\% en 2018. Este tipo de industria ha generado alrededor de 300 toneladas/día de residuos sólidos en Brasil. Esto indica un desafío medioambiental sobre cómo gestionar los residuos adecuadamente. Esta investigación tuvo como objetivo analizar la gestión de los residuos sólidos generados en el proceso de producción y los programas para minimizar los impactos ambientales de una industria del calzado en el estado de Ceará. La metodología utilizada se dividió en tres etapas: (i) cualitativa de residuos sólidos, (ii) cuantitativos y costos de residuos y (iii) evaluación de los programas de minimización de impacto de la empresa. En conclusión, hubo un almacenamiento adecuado, recolección y múltiples destinos finales para los residuos, con énfasis en el coprocesamiento y la reutilización de los residuos en otras etapas del proceso de producción. Se desarrollaron programas para minimizar los impactos ambientales a través de "D'Olho en la calidad"; "Energía y carbono"; y "Autocontrol de efluentes". El principal desafío de la compañía en la gestión de los residuos sólidos fue hacer que la visión sea más sistemática en las etapas del ciclo productivo de los sectores: el origen de las materias primas, opción por insumos alternativos, hacer que los procesos de transformación de productos sean más eficientes y expandir la logística inversa y los programas de responsabilidad post-uso.

PALABRAS-CLAVE: Industria de calzados. Residuos sólidos. Impactos ambientales. Gestión ambiental. 


\title{
Revista Científica ANAP Brasil
}

\author{
ISSN 1984-3240 - Volume 13, número 29, 2020
}

\section{INTRODUÇÃO}

As atividades industriais provocam inúmeros impactos positivos na economia e ganhos sociais para um país, em contrapartida, podem ser sinônimos de perdas ambientais consideráveis. 0 grande volume dos processos de produção desse setor gera resíduos sólidos como sobras de materiais ou produtos com falhas. A destinação incorreta desses resíduos poderá degradar o meio ambiente, oferecer riscos à saúde ou mesmo prejudicar o desenvolvimento da própria empresa. Essa situação aponta para um problema ambiental iminente sobre como gerir esses resíduos de forma adequada.

O gerenciamento desses resíduos sólidos deve passar por alguns processos mais gerais como de coleta, armazenamento, transporte, destinação e tratamento quando possível. Dependendo da situação pode ocorrer diretamente a reinserção das sobras e falhas dos materiais descartados sem necessitar de tratamento; podem ser designados para reciclagem, retornar como insumo de algum outro processo de produção da empresa ou, em último caso, pode ser descartado com destinação final em aterros sanitários.

Nesse contexto, destaca-se a indústria calçadista que segundo Relatório Anual das Atividades em 2019 da Associação Brasileira das Indústrias de Calçados (ABICALÇADOS), há pouco mais de 6 mil empresas no país, representando $4 \%$ do Produto Interno Bruto (PIB) da Indústria de Transformação do Brasil com faturamento de 21 bilhões em 2018 e produzindo 944 milhões de pares de sapatos no mesmo ano, com o país sendo o 40 maior produtor de calçados do mundo e o Estado do Ceará o maior produtor do país com $27 \%$ de toda a indústria calçadista brasileira em 2018 (ABICALÇADOS, 2019).

A fabricação de calçados possui diversas etapas e subetapas, como efeito tem-se a geração de 300 toneladas/dia de resíduos sólidos desse setor no país (SOARES; ARAÚJO, 2016). Isso indica um desafio na gestão de resíduos sólidos, porém, a própria produção científica da área de gestão de resíduos industriais é considerada baixa ${ }^{1}$, sendo um importante indicador para o pouco avanço nesse campo. Assim, esta pesquisa objetivou analisar a gestão de resíduos sólidos gerados no processo de produção e programas de minimização de impactos ambientais de uma indústria de calçados do Estado do Ceará. Para tanto, foram traçados os seguintes objetivos específicos: (i) identificar, quantificar e analisar os resíduos sólidos gerados de acordo com as destinações finais desses materiais e (ii) investigar os programas de minimização dos impactos ambientais desenvolvidos pela empresa.

\section{A GESTÃO AMBIENTAL NOS PROCESSOS PRODUTIVOS DO SETOR CALÇADISTA}

Os problemas relacionados à disposição final de resíduos sólidos gerados pela sociedade e também pelas indústrias têm trazido inúmeras discussões sobre o cumprimento de planos de gestão para que os impactos ambientais sejam minimizados. Um dos grandes problemas é o descarte de forma inadequada no meio ambiente de quantidades consideráveis de resíduos

\footnotetext{
${ }^{1}$ Os estudos de Deus, Battistelle e Silva (2015) sobre a produção científica voltada aos Resíduos sólidos no Brasil apontam que, no espaço de tempo entre 1993 a 2013, 10,43\% das produções foram voltadas para classificação dos resíduos industriais, $2,61 \%$ sobre suas destinações finais e nenhum dado foi apresentado sobre produções que enfocam a armazenagem desses materiais.
} 


\title{
Revista Científica ANAP Brasil
}

\author{
ISSN 1984-3240 - Volume 13, número 29, 2020
}

sólidos, já que a sociedade contemporânea tem consumido produtos e serviços que geram resíduos em excesso e que são descartados em locais inapropriados. esse é um dos motivos pelo qual o Brasil e muitos outros países procuram meios que viabilizem a realização da gestão adequada desses materiais.

Cabe destacar que o setor industrial possui uma significativa geração de resíduos sólidos, definidos pela Resolução do Conselho Nacional do Meio Ambiente - CONAMA no 313 (2002), como sendo todos os resíduos que sejam resultantes dos processos industriais nos estados sólido e semissólido, por exemplo. No caso da indústria calçadista, esses resíduos são provenientes de sobras ou falhas das matérias-primas na cadeia produtiva das suas atividades. As etapas básicas da cadeia produtiva das fábricas de calçados são: modelagem; classificação dos componentes do calçado; corte e chanfro ${ }^{2}$; preparação e costura; montagem; acabamento; verificação e expedição (SANTOS, 2008). Quanto às principais matérias-primas utilizadas na fabricação, há, aproximadamente, 40 tipos diferentes de materiais. As composições mais adotadas são $25 \%$ de couro, $17 \%$ de poliuretano (PU), 16\% de borracha termoplástica, $14 \%$ de etileno acetato de vinil (EVA), 8\% de policloreto de vinil (PVC), 7\% de borrachas, $7 \%$ de outros materiais (metais, por exemplo) e 6\% de materiais têxteis (STAIKOS et al., 2006, apud KOHL; REZENDES, 2016).

Como afirma Soares e Araújo (2016), os resíduos sólidos oriundos das sobras e falhas dessas matérias-primas podem ser descartados, reinseridos no processo produtivo ou destinados aos catadores de materiais recicláveis etc. A coleta, armazenagem e as destinações finais, quando realizadas inadequadamente, podem ocasionar impactos ambientais negativos, riscos à saúde humana e ao desenvolvimento da organização.

Desse modo, as indústrias calçadistas têm observado uma cobrança externa da sociedade civil e das legislações dos países, bem como internamente pela própria empresa a buscar práticas sustentáveis para os processos produtivos através de adequação à exigências de certificações de reconhecimento internacional e por ações que minimizem os impactos sobre o meio ambiente e o uso de recursos naturais (OLIVEIRA; SERRA, 2010).

As organizações têm adotado ações estratégicas e operacionais em todos os setores como a implantação dos Sistemas de Gestão Ambiental (SGA) a fim de diminuir a degradação do meio ambiente, aumentar a eficiência energética e das etapas de produção, melhorando o desempenho ambiental e beneficiando a imagem da empresa perante a sociedade (CAMPOS; MELO, 2008). A regulamentação desse processo de SGA no Brasil é realizado pelas Normas da ISO (International Organization for Standardization) em sua série 14.000 com o plano de gestão da empresa com o intuito de melhorar e examinar o nível de desempenho ambiental.

Como ações práticas, as organizações podem adotar as propostas de Ecoeficiência, que tem o objetivo de produzir mais, mas com equidade social e com menos recursos naturais em suas atividades como afirma a Comissão de Políticas de Desenvolvimento Sustentável - CPDS (CPDS, 2010). Um exemplo disso é a Rede de Produção Mais Limpa - RPML (RPML, 2010), em que se prevê a mudança nas formas de eliminação da poluição da cadeia produtiva, como impedir a liberação de emissões perigosas para o ar, água ou solo.

\footnotetext{
${ }^{2} \mathrm{O}$ ato de chanfrar compreende a redução e adequação da espessura do couro às exigências do modelo de calçado.
} 


\title{
Revista Científica ANAP Brasil
}

\author{
ISSN 1984-3240 - Volume 13, número 29, 2020
}

Uma ação que pode complementar e viabilizar a implantação da variável ambiental nas empresas é a Avaliação do Ciclo de Vida (ACV) que, em linhas gerais, quantifica e avalia o consumo de recursos e os possíveis impactos associados a um produto ou serviço em todo o seu ciclo de vida (DA SILVA; MORAES; MODOLO, 2015). Além disso, visa melhorar os processos produtivos para redução dos impactos ambientais por meio de técnicas e tecnologias ambientalmente adequadas em relação ao projeto, produção, uso e disposição dos produtos, por exemplo, no setor calçadista.

Como aponta Vieira e Barbosa (2011), as indústrias calçadistas, principalmente, de micro, pequeno e médio portes, com um perfil de baixa capacidade de investimento e as indústrias que fabricam produtos de baixo preço, que não possuem margem para agregar valor, sofrem com restrições para viabilizar práticas associadas à Ecoeficiência. A literatura indica desafios importantes para implantação de ações ambientais sistematizadas nas fábricas de calçados, entre eles: recursos humanos, físicos e financeiros e ausência de sensibilização das gerências das empresas sobre o assunto.

\section{METODOLOGIA}

A análise da gestão dos resíduos sólidos desta pesquisa foi realizada na filial de uma indústria calçadista brasileira, localizada na cidade de Morada Nova no Estado do Ceará. Atualmente a empresa possui 2.900 funcionários diretos e produz aproximadamente 450.000 pares de sapatos por ano.

A escolha dessa empresa justificou-se pelo fato de ser uma das maiores instaladas na cidade e por ser um setor poluente e gerador de resíduos. Assim, é importante analisar a sua gestão de resíduos sólidos por meio de dados gerados pela empresa.

A análise do processo produtivo da fábrica foi realizada por meio da coleta de dados quantitativos e qualitativos do período de outubro de 2017 a outubro de 2018, buscando extrair quais os tipos de resíduos sólidos gerados, se há necessidade de tratamento, quais as formas de armazenagem e destinação final adotados pela empresa e quais os programas de minimização de impactos ambientais implementados pela empresa.

Os dados quantitativos foram disponibilizados por meio de documentos concedidos pela empresa no período de 13 meses. Dessa forma, para execução da pesquisa, o percurso metodológico foi dividido em três etapas com suas respectivas ações, conforme apresentado na Figura 1. 


\section{Revista Científica ANAP Brasil}

ISSN 1984-3240 - Volume 13, número 29, 2020

Figura 1 - Divisão das etapas e ações do percurso metodológico do estudo.

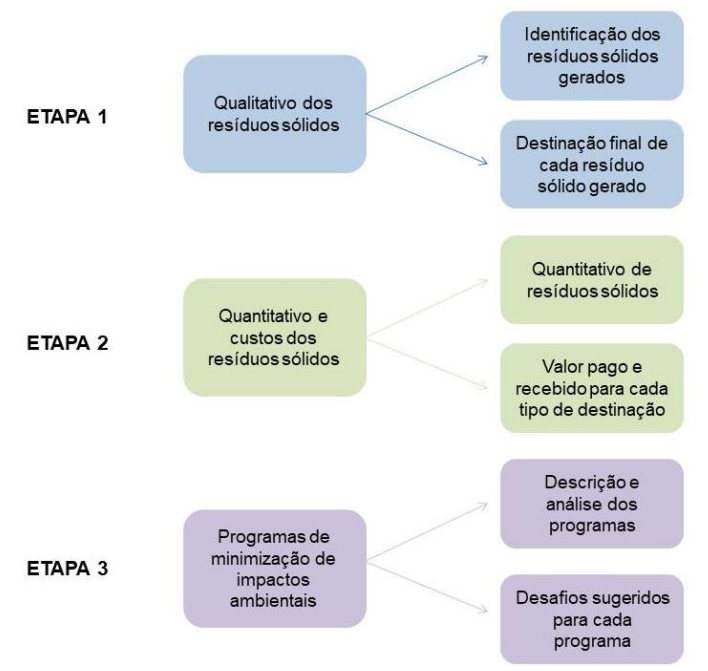

Fonte: ELABORADO PELOS AUTORES, 2020.

Na etapa 1, sobre os qualitativos dos resíduos sólidos, foram analisados dados disponibilizados pela organização investigada. Dessa forma, foi possível identificar os tipos de resíduos sólidos que foram gerados no processo produtivo da indústria calçadista, bem como suas respectivas destinações finais.

$\mathrm{Na}$ etapa 2, sobre o quantitativo e custo dos resíduos sólidos, foram quantificados a partir de documentos disponibilizados pela empresa durante 13 meses, compreendendo o período de outubro de 2017 a outubro de 2018. O quantitativo dos resíduos gerados foi dado em massa. Nesta etapa, o investimento para destinação final de cada tipo de resíduo sólido também foi investigado.

$\mathrm{Na}$ etapa 3, sobre os programas de minimização de impactos, foram apresentados e analisados os três tipos de programas de monitoramento de minimização de impactos realizados pela indústria. A ideia foi descrever cada programa com suas respectivas finalidades além de apresentar uma avaliação geral dos programas e ações, apontando alguns desafios para a organização desses programas. 


\section{Revista Científica ANAP Brasil}

ISSN 1984-3240 - Volume 13, número 29, 2020

\section{GERENCIAMENTO DOS RESÍDUOS SÓLIDOS NA INDÚSTRIA}

A indústria de calçados investigada apresentou ações ambientais quanto aos resíduos sólidos, detendo um Plano de Gerenciamento de Resíduos Sólidos - PGRS e elaborado de acordo com o termo de referência emitido pela Superintendência Estadual do Meio Ambiente - SEMACE, atendendo a Lei № 16.032 (CEARÁ, 2016), onde está descrito os tipos de resíduos gerados, acondicionamento e destinação final adequada às legislações.

No período de análise, a indústria teve sua coleta dos resíduos sólidos acondicionada na central de resíduos da própria empresa que possuía coletores distribuídos nos setores obedecendo aos padrões de cores estabelecidos na Resolução CONAMA n 257 (2001). O transporte e as destinações finais foram realizados por empresas contratadas em regime de terceirização, na qual as destinações variaram de acordo com o tipo de material.

As destinações finais oriundas dos processos produtivos desta empresa foram: (1) reciclagem externa realizada por uma cooperativa do município de Morada Nova, ao transformar materiais usados em novos fora da indústria analisada e (2) reaproveitamento dos resíduos na própria empresa com a utilização de materiais residuais em outros processos produtivos.

Assim como foram adotados o (3) coprocessamento, em que há a integração entre o processo de queima de resíduos sólidos e ocorre a fabricação de produtos que demandam altas temperaturas em sua produção; (4) logística reversa, na qual a empresa garantia o retorno para o processo produtivo dos produtos pós-uso e (5) aterro sanitário, quando o resíduo não conseguia se encaixar em nenhuma das alternativas anteriores e era então considerado rejeito. A Tabela 1 mostra os tipos de resíduos sólidos e suas respectivas destinações finais da empresa analisada. $O$ destaque foi a diversidade de materiais que passam pelo coprocessamento, que representa um processo de queima, devido a impossibilidade de inserção de materiais como panos contaminados com óleo em outros processos menos danosos, como reciclagem ou reaproveitamento interno como acontece com resíduos de solas de calçados. 


\title{
Revista Científica ANAP Brasil
}

\author{
ISSN 1984-3240 - Volume 13, número 29, 2020
}

Tabela 1: Tipos de materiais com as respectivas destinações finais.

\begin{tabular}{ll}
$\begin{array}{l}\text { Tipos de destinações } \\
\text { finais }\end{array}$ & \multicolumn{1}{c}{ Materiais } \\
\hline $\begin{array}{l}\text { Reciclagem externa } \\
\text { Reaproveitamento } \\
\text { interno na própria } \\
\text { indústria }\end{array}$ & $\begin{array}{l}\text { pesíduos de sola falhada e rebarbas de sola, contraforte e cunho. } \\
\text { Coprocessamento }\end{array}$ \\
$\begin{array}{l}\text { panos contaminados com óleo, graxa e solvente; resíduos de papelão e } \\
\text { plástico contaminados com insumos químicos; resíduos de borrachas com } \\
\text { defeito, Equipamentos de Proteção Individual - EPIs (luvas, máscaras, } \\
\text { botas, óculos, embalagens de creme de proteção) e resíduos de tecido, } \\
\text { forro, espumado, sintético e couro. }\end{array}$ \\
$\begin{array}{l}\text { Logística reversa } \\
\text { pares de calçados produzidos pela própria empresa após o uso. }\end{array}$ \\
$\begin{array}{l}\text { embalagens de recheados, pipocas e bombons, fitas durex, fita gomada, } \\
\text { papel toalha, guardanapo e papel higiênico, resíduo de varrição, restos de } \\
\text { linha e pó de lixação. }\end{array}$
\end{tabular}

Fonte: DADOS EXTRAÍDOS DA UNIDADE INDUSTRIAL ANALISADA - PERÍODO OUT. 2017 A OUT. 2018.

Em relação ao quantitativo dos resíduos em pesagem (quilograma) por participação nas destinações finais presentes na empresa (porcentagem), teve-se que a maioria realmente tem o coprocessamento como modo de destinação com quase a metade bruta dos materiais totais (48\%). Ressalta-se o reaproveitamento interno de resíduos em outros processos da empresa que não o de origem do material, que representou $29 \%$ do total. Notou-se que a logística reversa teve participação pouco representativa nas destinações, sendo $1 \%$ do valor.

Gráfico 1: Quantitativo em porcentagem de resíduos em relação as destinações finais adotadas na indústria.

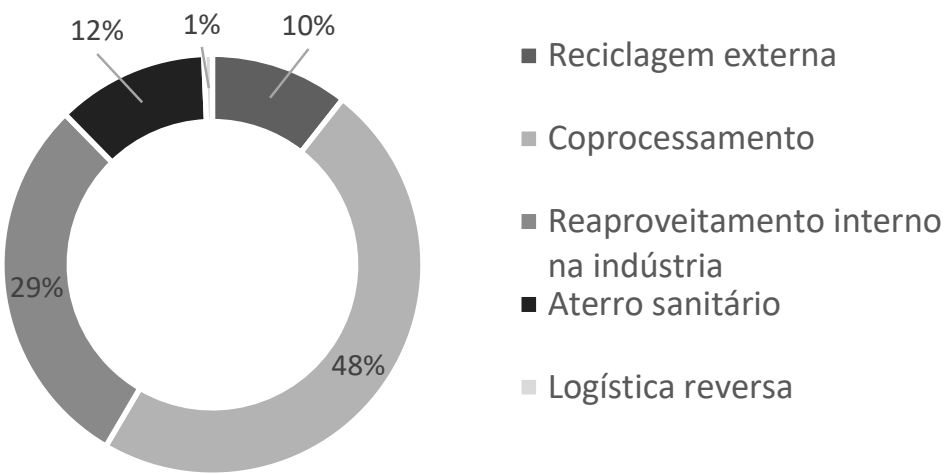

Fonte: DADOS EXTRAÍDOS DA UNIDADE INDUSTRIAL ANALISADA - PERÍODO OUT. 2017 A OUT. 2018.

Os dados brutos da empresa presentes na tabela 2 apresentaram a pesagem em quilograma de resíduos por cada tipo de destinação e seus custos e economias respectivos. Os ganhos monetários diretos nas destinações finais foram representados pela reciclagem externa e logística reversa. A primeira pela cooperativa do município que tem como retorno um abatimento de pouco mais de 10 mil reais na conta mensal de energia elétrica da indústria. 0 


\section{Revista Científica ANAP Brasil}

ISSN 1984-3240 - Volume 13, número 29, 2020

ganho monetário com a logística reversa ainda é baixo devida a participação reduzida desse tipo de destinação.

Tabela 2: Quantitativo e valores financeiros das destinações finais desenvolvidas.

\begin{tabular}{lccc}
\hline $\begin{array}{c}\text { Tipo de destinação final } \\
\text { dos resíduos }\end{array}$ & Total $(\mathbf{k g})$ & Total pago (R\$) & Total recebido (R\$) \\
\hline Reciclagem externa & $59.895,59$ & - & $10.230,37^{*}$ \\
Coprocessamento & $269.808,69$ & $233.080,20$ & - \\
$\begin{array}{l}\text { Reaproveitamento } \\
\text { interno na empresa }\end{array}$ & $164.848,90$ & - & - \\
Aterro Sanitário & $65.844,45$ & $164.043,73$ & $2.001,30$ \\
Logística reversa & $3.735,60$ & - & $12.231,67$ \\
\hline
\end{tabular}

*Valor convertido em desconto na conta de energia elétrica da indústria.

Fonte: DADOS EXTRAÍDOS DA UNIDADE INDUSTRIAL ANALISADA - PERÍODO OUT. 2017/ OUT. 2018.

Os custos com o coprocessamento foram de cerca de $\mathrm{R} \$ 0,86$ por quilograma de resíduo. No aterro sanitário foram destinados os rejeitos envolvendo diversos custos, por exemplo, o de transporte até o aterro, o custo por cada quilograma de resíduos foi de $R \$ 2,49$, se mostrando como uma alternativa ambientalmente adequada mais custosa do que o coprocessamento que acontece in loco na fábrica. Enquanto isso, o reaproveitamento interno de resíduos na própria empresa com a utilização de materiais residuais em outros processos produtivos, como solas falhadas de calçados, não apresentou custos ou injeção de ganhos monetários diretos.

\section{PROGRAMAS DE MINIMIZAÇÃO DE IMPACTOS AMBIENTAIS IMPLEMENTADOS}

No contexto dos programas de minimização de impactos ambientais, a indústria desenvolveu ações de educação ambiental com todos os colaboradores. Após a admissão, recebia-se treinamento dos setores da fábrica, incluindo o de gestão ambiental. Nesses treinamentos apresentava-se o PGRS, as disposições corretas dos resíduos, tipos de resíduos, controle de água, efluente, energia e carbono.

Como ações de gestão ambiental da empresa teve-se os automonitoramentos realizados semestralmente para a SEMACE. Eles seguiram as condicionantes fixadas na expedição do licenciamento ambiental na fase de Licença de Operação da empresa. Para este estudo convencionou-se apresentar três programas realizados pela indústria: Energia e Carbono; Automonitoramento de Efluentes e o D'Olho na Qualidade.

O Programa de Energia e Carbono visou minimizar o desperdício de energia utilizada durante a execução das atividades e controle das emissões atmosféricas. A empresa comprou energia (eólica ou solar) do Mercado Livre que, consequentemente, contribuiu para redução/eliminação de poluentes emitidos para atmosfera como, por exemplo, o $\mathrm{CO} 2$. O resultado entre outubro de 


\title{
Revista Científica ANAP Brasil
}

\author{
ISSN 1984-3240 - Volume 13, número 29, 2020
}

2017 a outubro de 2018 foi a redução de 553,64 toneladas desses gases, não tendo sido informado o quanto desses gases poluentes ainda são produzidos pela empresa mesmo após a implementação do programa, o que dificultou entender o impacto direto causado por ele.

O Programa de Automonitoramento de Efluentes que tratou diretamente sobre resíduos líquidos, teve periodicidade de medição diária a partir das leituras dos hidrômetros para controle da vazão de água consumida e de efluente gerados em $\mathrm{m}^{3} /$ dia. A Empresa tinha uma Estação de Tratamento de Efluentes que atendia aos padrões da Resolução do Conselho Estadual de Meio Ambiente - COEMA № 02 (2017), podendo contar com análises diárias, semanal ou trimestral de acordo com a necessidade de monitoramento de cada parâmetro. Do total de efluentes tratados, $95 \%$ dele foi reutilizado para atividades menos nobres, por exemplo, descargas dos sanitários, rega de área verde, reduzindo o consumo de água potável e os custos e os $5 \%$ restantes foi lançado em corpos hídricos da região.

Enquanto isso, o Programa D'Olho na Qualidade foi uma adaptação da política dos 5s (Repensar, Recusar, Reduzir, Reutilizar e Reciclar) e implementado na indústria desde 2014. O intuito foi otimizar os espaços; melhorar as condições no ambiente de trabalho; evitar desperdícios; aumentar a qualidade dos produtos; o rendimento do trabalho; incentivar o trabalho em equipe e trabalhar de forma sustentável. Nesse programa cada letra do nome significa uma fase a ser executada: D - Descarte, O - Organização, L - Limpeza, H - Higiene e O - Ordem mantida. O programa foi organizado de acordo com a Figura 2, onde cada setor é avaliado pelo menos três vezes por mês e, posteriormente, realizado o fechamento da nota de desempenho do respectivo setor a partir da escala da Tabela 3.

Cada setor tem os seus representantes de acordo com a Figura 2. Mensalmente foram organizadas reuniões conforme o calendário anual elaborado pela organização. Com isso, foram discutidas as notas, melhorias e situação vigente de cada setor separadamente, mas de forma a reunir todos os colaboradores da respectiva área. Em seguida, a Comissão do programa (representantes de cada setor) juntamente com a coordenação da empresa, avaliavam os resultados de cada setor e definiam ações para todos os membros, desde os representantes de cada setor até os seus colaboradores. 


\section{Revista Científica ANAP Brasil}

ISSN 1984-3240 - Volume 13, número 29, 2020

Figura 2: Organograma referente à constituição do Programa D’Olho na Qualidade.

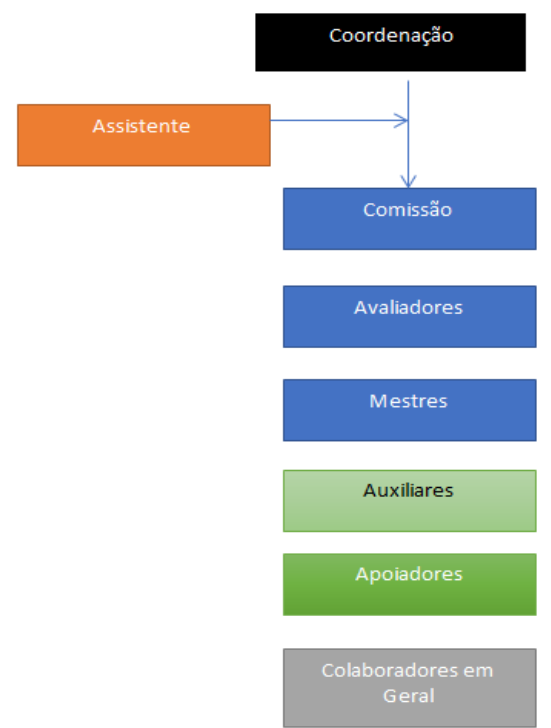

Fonte: DADOS EXTRAÍDOS DA UNIDADE INDUSTRIAL ANALISADA - PERÍODO OUT. 2017/ OUT. 2018.

Especificamente sobre as pontuações atribuídas a cada setor, era feita avaliação primeiramente por uma dupla (mestre + auxiliar) designada pela coordenação. Essas duplas deveriam avaliar o seu setor designado utilizando um checklist padrão em três semanas distintas de cada mês. A análise setorial era iniciada com pontuação máxima de 100 pontos e conforme apareciam as inconformidades, os pontos eram descontados. Como resultado, tinha-se a nota final atribuída ao setor.

No final de cada mês, tinha-se a média aritmética obtida a partir das três avaliações. Depois de atribuída a nota, a dupla do setor juntamente com a sua equipe deveria trabalhar os pontos negativos e manter a ordem com os pontos positivos. $O$ intuito era sempre a ordem mantida e o progresso do setor de forma coletiva e harmônica.

Tabela 3: Escala de pontuação das notas de desempenho.

\begin{tabular}{ccc}
\hline \multicolumn{2}{c}{ Escala de pontuação } & \\
\hline Ação Imediata necessária & Vermelho & 0 - 50 pontos \\
Abaixo dos padrões mínimos & Amarelo & 51 - 70 pontos \\
Setor em boas condições & Bronze & 71 - 84 pontos \\
\hline Comprometida com a melhoria contínua & Prata & 85 - 94 pontos \\
\hline Líder em 5s - Autogerencia-se & Ouro & $95-100$ pontos \\
\hline Fonte: DADOS EXTRAÍDOS DA UNIDADE INDUSTRIAL ANALISADA - PERÍODO OUT. 2017/ OUT. 2018.
\end{tabular}




\title{
Revista Científica ANAP Brasil
}

\author{
ISSN 1984-3240 - Volume 13, número 29, 2020
}

A partir da Tabela 3 eram identificadas as posturas dos setores, sendo a pontuação 84 o limite entre essas posturas. A nota considerada bronze ou inferior (até 84 pontos) indicava a necessidade da elaboração de um plano de ações com prazos definidos logo após o recebimento da nota final. Na reunião seguinte da Comissão, os setores com até essa pontuação deveriam apresentar as melhorias alcançadas e solicitar ajuda externa, caso necessário.

Destaca-se que o setor com nota prata ou ouro (acima de 84 pontos) não recebia premiação ou abonos financeiros, pois a ideia da organização era tornar a autoavaliação e o desejo de melhoria coletiva um hábito diário entre os colaboradores, por meio da apresentação dos resultados alcançados e os benefícios de se trabalhar em um local mais confortável e organizado, por exemplo. Assim, o setor com essa nota era classificado como comprometido com a melhoria contínua ou ainda como um setor que realizava o autogerenciamento, trazendo reconhecimento e estimulando à manutenção da nota.

\section{CONSIDERAÇÕES FINAIS}

Esta pesquisa apresentou a contribuição quanto à investigação da gestão de resíduos sólidos aplicada a uma indústria calçadista. Observou-se que o armazenamento e coleta dos resíduos foram realizados de forma adequada com as legislações ambientais vigentes. Destacam-se as múltiplas destinações finais, sendo a maioria do quantitativo desses resíduos destinados a diferentes etapas do processo produtivo da própria empresa, como por meio do coprocessamento (resíduos do tipo graxa e solvente, papelão e plástico contaminados com insumos químicos) e reaproveitamento interno direto (resíduos de sola falhada e rebarbas de sola), reduzindo custos e representando ganhos ambientais significativos ao demandar menos recursos naturais externos.

Sobre os programas de gestão ambiental para a minimização dos impactos, constatou-se que em relação aos impactos diretos, há o Programa "D'olho na Qualidade", por meio do envolvimento dos funcionários de todos os setores da empresa, mostrou-se a contínua preocupação e busca por processos produtivos mais respeitosos com o meio ambiente. No entanto, um desafio seria que o programa pudesse ser expandido de maneira a atingir também a sociedade, por meio de programas de educação ambiental em parceria com as escolas do município e Organizações não Governamentais (ONGs), buscando ultrapassar os limites da empresa e ganhar a comunidade.

O programa de "Automonitoramento de Efluentes" pode ser considerado eficiente sob suas ações de reutilização dos efluentes para atividades menos nobres da empresa. Assim como o Programa de "Energia e Carbono" mostrou-se como uma ação eficiente sob o ponto de vista da compra de energia de fontes limpas, como a eólica e solar, que resultou na diminuição da emissão de gases do efeito estufa. No entanto, esse poderia ser ampliado por meio da instalação de células fotovoltaicas nas dependências da empresa, aproveitando o potencial natural da região como forma de complementar a geração de outras fontes já existentes. Isso significaria que a indústria não só comprasse créditos de energia, mas produzisse a sua própria, inclusive podendo vender possíveis excedentes.

Como desafio geral para o gerenciamento dos resíduos sólidos, aponta-se a ideia de se discutir todo o ciclo produtivo da empresa com o intuito de tornar a visão sobre os resíduos mais 


\title{
Revista Científica ANAP Brasil
}

\author{
ISSN 1984-3240 - Volume 13, número 29, 2020
}

sistemática, como por exemplo, pela implementação da Avaliação do Ciclo de Vida (ACV). O desafio para a indústria analisada seria principalmente pensar e repensar a origem das matériasprimas, opção por materiais alternativos, tornar mais eficientes os processos de transformação dos produtos, ampliar os programas de logística reversa e responsabilidade pós-uso, dentre outros.

\section{REFERÊNCIAS}

BRASIL. Resolução do Conselho Nacional do Meio Ambiente (CONAMA) № 257, de 25 de abril de 2001. Estabelece o código de cores para os diferentes tipos de resíduos a ser adotado na identificação de coletores e transportadores, bem como nas campanhas informativas para a coleta seletiva. Brasília, DF: Diário Oficial da União (DOU), 19 jun. 2001. Disponível em: <http://www.siam.mg.gov.br/sla/download.pdf?idNorma=291>. Acesso em: 16 abr. 2020.

BRASIL. Resolução do Conselho Nacional do Meio Ambiente (CONAMA) no 313, de 29 de outubro de 2002. Dispõe Sobre $O$ Inventário Nacional de Resíduos Sólidos Industriais. Brasília, DF: Diário Oficial da União (DOU), 22 nov. 2002. Disponível em: <http://www2.mma.gov.br/port/conama/legiabre.cfm?codlegi=335>. Acesso em: 05 abr. 2020.

CAMPOS, Lucila Maria de Souza; MELO, Daiane Aparecida de. Indicadores de desempenho dos Sistemas de Gestão Ambiental (SGA): uma pesquisa teórica. Production, [s.I.], v. 18, n. 3, p. 540-555, dez. 2008. Disponível em: <scielo.br/scielo.php?script=sci_arttext\&pid=S0103-65132008000300010>. Acesso em: 23 mar. 2020.

CEARÁ. Resolução do Conselho Estadual de Meio Ambiente (COEMA) no 2, de 02 de fevereiro de 2017. Dispõe Sobre Padrões e Condições Para Lançamento de Efluentes Líquidos Gerados Por Fontes Poluidoras. Fortaleza, CE: Diário Oficial do Estado (DOE), Disponível em: https://www.legisweb.com.br/legislacao/?id=337973. Acesso em: 01 abr. 2020.

CEARÁ. Lei do Governo do Estado do Ceará no 16032, de 20 de junho de 2016. Institui A Política Estadual de Resíduos Sólidos no âmbito do Estado do Ceará. Fortaleza, CE: Diário Oficial do Estado (DOE), 22 jun. 2016. Disponível em: <http://www.mpce.mp.br/wp-content/uploads/2015/12/Lei-Estadual-n\%C2\%BA16.032-2016Institue-a-Pol\%C3\%ADtica-Estadual-de-Res\%C3\%ADduos-S\%C3\%B3lidos-no-Estado-do-Cear\%C3\%A1.pdf>. Acesso em: 01 abr. 2020.

CPDS. Comissão De Políticas De Desenvolvimento Sustentável (CPDS). Agenda 21 brasileira. 2020. Disponível em: http://www.cntdespoluir.org.br. Acesso em: 15 abr. 2020.

DEUS, Rafael Mattos; BATTISTELLE, Rosane Aparecida Gomes; SILVA, Gustavo Henrique Ribeiro. Resíduos sólidos no Brasil: contexto, lacunas e tendências: contexto, lacunas e tendências. Engenharia Sanitária e Ambiental, [s.l.], v. 20, n. 4, p. 685-698, dez. 2015. Disponível em: <http://www.scielo.br/scielo.php?script=sci_arttext\&pid=S141341522015000400685>. Acesso em: 15 abr. 2020.

ABICALÇADOS. Relatório anual de atividades de 2019. Novo Hamburgo: Abicalçados, 2019. 65 p. Disponível em: $<$ http://abicalcados.com.br/publicacoes/?utm_source=Contatos+Abical\%25C3\%25A7ados\&utm_campaign=b60a2e 33ec-EMAIL_CAMPAIGN_2018_01_17_COPY_01\&utm_medium=email\&utm_term=0_7f566382b3-b60a2e33ec320993059>. Acesso em: 02 abr. 2020.

KOHL, Claudia Adriana; KLAUCK, Mônica. Levantamento de aspectos e impactos ambientais em uma indústria calçadista do Vale do Sinos/RS. In: FÓRUM INTERNACIONAL DE RESÍDUOS SÓLIDOS, 7., 2016, Porto Alegre. Anais do 70 Fórum Internacional de Resíduos Sólidos. Porto Alegre: Instituto Venturi Para Estudos Ambientais, 2016. Disponível em: <http://institutoventuri.org.br/ojs/index.php/firs/article/view/83>. Acesso em: 02 abr. 2020.

OLIVEIRA, Otávio José de; SERRA, José Roberto. Benefícios e dificuldades da gestão ambiental com base na ISO 14001 em empresas industriais de São Paulo. Production, [s.l.], v. 20, n. 3, p. 429-438, 26 mar. 2010. Disponível em: <http://www.scielo.br/scielo.php?script=sci_arttext\&pid=S0103-65132010000300011>. Acesso em: 25 mar. 2020. 


\title{
Revista Científica ANAP Brasil
}

\author{
ISSN 1984-3240 - Volume 13, número 29, 2020
}

SANTOS, Ronise Ferreira dos. Investigação do método de desenvolvimento de calçados no pólo calçadista do Vale do Rio dos Sinos e Paranhama no estado do Rio Grande do Sul. 2008. 241 f. Dissertação (Mestrado) - Curso de Programa de Pós-graduação em Engenharia de Produção, Escola de Engenharia, Universidade Federal do Rio Grande do Sul, Porto Alegre, 2008. Disponível em: <https://lume.ufrgs.br/handle/10183/15837>. Acesso em: 02 mar. 2020.

SILVA, Adriana Hoenisch da; MORAES, Carlos Alberto Mendes; MODOLO, Regina Célia Espinosa. Avaliação Ambiental do setor calçadista e a aplicação da Análise de Ciclo de Vida: uma abordagem geral. In: Fórum Internacional de Resíduos Sólidos, 6., 2015, São Paulo. Anais do 60 Fórum Internacional de Resíduos Sólidos. São José dos Campos: Instituto Venturi Para Estudos Ambientais, 2017. p. 1-2. Disponível em:

<http://www.institutoventuri.org.br/ojs/index.php/firs/article/view/578>. Acesso em: 07 mar. 2020.

SOARES, Eliseu Afonso; ARAÚJO, Geraldino Carneiro de. Gestão De Resíduos Sólidos No Processo Produtivo: um estudo de caso em uma indústria calçadista. Revista da Universidade Vale do Rio Verde, [s.I.], v. 14, n. 2, p. 171181, 2016. Universidade Vale do Rio Verde (UninCor). Disponível em:

<http://periodicos.unincor.br/index.php/revistaunincor/article/view/2622>. Acesso em: 07 mar. 2020.

VIEIRA, Elias Antônio; BARBOSA, Agnaldo de Souza. Práticas Tradicionais e de Ecoeficiência na Indústria de Calçados no Brasil. Revista Eletrônica: Tempo - Técnica - Território, [s.I.], v. 2, n. 1, p. 30-50, maio 2011. Disponível em: <https://periodicos.unb.br/index.php/ciga/article/view/15418>. Acesso em: 19 mar. 2020.

REDE DE PRODUÇÃO MAIS LIMPA - RPML. Rede de Produção Mais Limpa. Guia da produção mais limpa. Rio de Janeiro: Conselho Empresarial Brasileiro Para O Desenvolvimento Sustentável - CEBDS, 2020. 55 p. Disponível em: <http://www.gerenciamento.ufba.br/Downloads/guia-da-pmaisl.pdf>. Acesso em: 19 mar. 2020. 